\title{
Oxydoras kneri as a Potential Candidate for the Biological Control of Mosquito-Vector Tropical Diseases
}

\author{
Ana Lucia Maria Ribeiro ${ }^{1}$, Fabio Alexandre Leal-Santos ${ }^{1,2, *}$, Paulo Roberto Soares ${ }^{1}$, \\ Adriana Carneiro da Silva Martins ${ }^{1}$, Arestides Massao Nachi $^{2}$, Anagela Maria Acel ${ }^{1}$, \\ Jorge Senatore Vargas-Rodrigues ${ }^{1}$, Eucilene Alves Santana Porto ${ }^{4}$ and \\ Cor Jesus Fernandes Fontes, ${ }^{2,3}$
}

${ }^{I}$ Laboratory of Entomology/Faculty of Medicine - Federal University of Mato Grosso (UFMT), Cuiaba; ${ }^{2}$ Laboratory of
Embriology/Faculty of Medicine - Federal University of Mato Grosso (UFMT), Cuiaba; ${ }^{3}$ Laboratory of Malaria/Julio
Müller University Hospital (HUJM), Brazil; ${ }^{4}$ Ministry of Health, MH/UNESCO, Brazil

\begin{abstract}
In this study, we assessed the larvivorous activity of Oxydoras kneri against Culicinae larvae in laboratory experiments to evaluate their suitability as a biological control. First, analysis of stomach content was performed to verify the feeding habits of the fish in their natural habitat. The behavior was then verified in aquarium experiments by feeding 2700 larvae to each fish. The feeding preference of the fish was evaluated in further experiments in which larvae and commercial fish food were offered, either separately or simultaneously. For both methods, the evaluation was performed by counting the number of adult mosquitoes that emerged during a 60 -h observation period. The laboratory was maintained at relatively stable temperature and humidity. The stomach content of 9 specimens of $O$. kneri captured in the Cuiabá River contained 26.5\% insect larvae, with $11.5 \%$ exclusively from Diptera insects. The emergence of adults from insect larvae was not influenced by the presence of $O$. kneri. However, emergence was statistically lower in aquaria when the larvae were placed as food for the fish. The consumption of larvae and granulated commercial fish food was similar during a 60 -h observation period, even when these items were offered separately or simultaneously. Since $O$. kneri are ubiquitous in the Amazon region, this finding highlights their potential role in the biological control of Culicidae mosquito larvae growing in fish farm tanks. However, further studies are required to evaluate their behavior in the field and the operational difficulties of their use as a biological control.
\end{abstract}

Keywords: Larvivorous behavior, mosquito biological control, Oxydoras kneri, Culicidae, fish.

\section{INTRODUCTION}

Despite only a few studies, mainly on the natural breeding sites of insects, fish have been used worldwide to control insect-vector diseases, such as malaria, yellow fever, and dengue, for a number of years $[1,2]$. Attempts to use larvivorous fish has already yielded success in some studies, especially with species such as Gambusia spp. and Poecilia reticulate (Peters, 1859) [1], which are exotic fauna. However, these species are not adequate for introduction into the Amazon Basin.

Fish farms have become increasingly popular, and, in recent years, have been used throughout Brazil for commercial purposes. Because of their characteristics, pisciculture tanks have allowed for the formation of anopheline breeding sites, thus contributing to the increase in the density of malaria vectors and the maintenance of the mosquito population when natural breeding sites for such insects disappear [3,4]. In addition, abandonment of fish farms, which is not uncommon, leads to the proliferation of vegetation inside the tanks, allowing for the increased proliferation of mosquitoes and malaria vectors [5].

*Address correspondence to this author at the Laboratory of Malaria/Julio Müller University Hospital (HUJM), Mato Grosso, Brazil; Tel/Fax: 55 65 3615-7253; Email: alexandre3025@gmail.com
The Oxydoras genus belongs to the family Doradidae and the order Siluriforme, and is distributed throughout the Araguaia (Oxydoras niger [Valenciennes, 1821]) and Prata (Oxydoras kneri [Bleeker, 1862]) Brazilian basins. A study on $O$. kneri showed that this species has diverse food sources with preferences based on temporal availability, including Diptera larvae [6]. These findings are in agreement with those of another study that classified $O$. kneri as an omnivorous fish [7]. This evidence infers that $O$. kneri has the potential for use in pisciculture as a predator of insect larvae for public health purposes. Thus, we assessed the larvivorous activity of $O$. kneri fish against Culicid larvae by using laboratory experiments, to evaluate their use in the control of insect-vector tropical diseases, both in nature and in pisciculture tanks.

\section{MATERIALS AND METHODOLOGY}

This study was conducted between September 2006 and December of 2007, during which 6 field excursions were performed with a fisherman to collect $O$. kneri fish in the region and 36 fish were captured. After being introduced into the research environment in the laboratory, these fish required an adaptation period of approximately 5 days, which was evidenced by the return to voracious eating of foods such as earthworm fragments or fish filet, corn, and soy. 
During this phase, it was observed that the fish preferred the earthworm fragments or fish filet. However, experiments performed after the adaptation phase demonstrated a satisfactory consumption of granulated fish food used in pisciculture. For this reason, during the research period, the fish that adapted to the aquaria were fed daily with $4 \mathrm{~g}$ ( $\sim 20$ pellets) of extruded floating fish food (PopFish-28, Maravilha Ind. Com. Rações Ltda., Cuiabá, Mato Grosso) per animal. During the adaptation period, it was also observed that these animals were more active and voracious in the absence of light. For that reason, later experiments were always conducted with maximum reduction of light.

\section{Capture and Adaptation of $O$. kneri in Aquaria}

Between May and December 2007, specimens of $O$. kneri were captured with fish poles and nets at different sites along the Cuiabá River Basin in the municipalities of Rosário Oeste, Nobres, Barão de Melgaço, and Cuiabá, in the state of Mato Grosso. These captures were authorized by the Mato Grosso State Secretary of the Environment, under document number 06848/2006, and the project was evaluated and approved by the Ethics Committee for Animal Research of the Federal University of Mato Grosso, under Protocol number 23108.007647/09-8.

Of the captured fish, 9 specimens were reserved for analysis of stomach content, and the remaining fish were transported to the research laboratory in closed, insulated polyethylene boxes that received continuous aeration through air pumps. At the laboratory, the fish were transferred to 500-L fiberglass tanks for a minimum of $48 \mathrm{~h}$ in order to adapt to their new environment. These tanks contained water and rocks collected in the river and were placed in an area of the laboratory with adequate light and ventilation. All the research experiments were performed in the Medical Embryology and Entomology Laboratories of the School of Medicine of the Federal University of Mato Grosso, Cuiabá.

For the experiments, the fish were transferred to glass tanks measuring $0.50 \mathrm{~m}$ in depth and $0.40 \times 0.40 \mathrm{~m}$ (volume, $\sim 80 \mathrm{~L})$. The tanks were lined with river rocks and covered with nylon screens, simulating the fish's natural habitat, at a ratio of 1 fish per tank. The experiments were only initiated after a 24-h re-adaptation period in the new tanks; the adaptation was confirmed by the observation of the fish's voracious appetite for corn, soy, fragments of other fish, and earthworms, which were suggested by the fishermen of the region.

In order to ensure that the levels of oxygen in the water were satisfactory, aquarium aerator pumps were used, with a capacity of $500 \mathrm{~L} / \mathrm{h}$. Water and air temperatures, as well as air humidity, were monitored daily-early morning, early afternoon, and late afternoon-throughout the research period. The laboratory was climate-controlled, in order to avoid extreme oscillation of these parameters. All experiments used adult fish of both genders, weighing approximately 400 $\mathrm{g}$ and with an average length of $35 \mathrm{~cm}$.

\section{Evaluation of the Stomach Content of O. kneri Fish}

From each capture, 1 or 2 specimens of the fish were killed for evaluation of the stomach content. The different foods found in the stomach were separated and classified according to the guidelines set by previous studies [7], and the volume was measured in small beakers. To evaluate the larvivorous activity of $O$. kneri, several trips were conducted to capture mosquito larvae and adults, initially of the Anopheles species, in the municipalities of Chapada dos Guimarães, Santo Antonio do Leverger, and Barão de Melgaço, all on the outskirts of Cuiabá, MT. The larvae were collected using ladles and the adult mosquitoes were collected using 2 researchers as attractants (ALMR and JSVR), with restricted exposure. The region where the insects were collected is not endemic for malaria, which favored the decision to adopt this method of collection. However, after several attempts to collect the larvae and capture the insects, there were not enough specimens of Anopheles spp. to perform the experiments with this genus, so we opted for continuing the investigation using other mosquitoes belonging to Culicidae. Therefore, the experiments for larvivorous behavior in this study were performed using mainly mosquitoes of the Culicinae subfamily, Culex spp. and Aedes (Ochlerotatus) fluviatilis (Lutz, 1904) species. The larvae and adult mosquitoes collected in the field, as well as the existing colony in the laboratory, were maintained according to the methods used by Consoli \& Lourenço-de-Oliveira [8].

\section{Evaluation of the Development of Larvae into Adult Cu- licine Mosquitoes}

A certain influence of the fish on the larval development of culicines [7,9] in aquaria is expected. This interference could skew the results, since the experiments to assess the larvivorous behavior are controlled in aquaria containing larvae in the absence of $O$. kneri. To ensure that this phenomenon would not occur in this study, we opted for comparing the emerging times adult insects from larvae by submitting the larvae to both the presence and the absence of the fish in the experimental aquaria. This experiment was repeated 3 times by using 100 larvae per aquarium. We defined the emerging time of the adult insects from the larvae as the period that elapsed between several ecdyses of the larvae and the evidence of metamorphosis of the pupae into winged insects.

Larvae of culicines in the $\mathrm{L}_{3}$ and $\mathrm{L}_{4}$ stages were placed in 2 aquaria (100 larvae per aquarium), one with $O$. kneri and the other without. The larvae were placed inside waterpermeable, insect-screened, and transparent receptacles, partially submerged in the water, to avoid larvae predation by the fish. These larvae were observed during 2 periods of the day, when the number of adult insects inside the receptacle was counted. Counting was only stopped when a minimum of $75 \%$ of the insects had emerged into the winged phase. The number of emerged winged insects and the time of such emergence were recorded for both aquaria.

\section{Evaluation of the Larvivorous Activity of $O$. kneri}

Three experiments were performed to observe larvivorous activity by adding 900 to $1000 \mathrm{~L}_{3}-\mathrm{L}_{4}$ culicine larvae and 1 fish to the $O$. kneri aquarium. To the control aquarium, only 900 to $1000 \mathrm{~L}_{3}-\mathrm{L}_{4}$ culicine larvae were added. The fish used in this experiment were not given food for $24 \mathrm{~h}$, to ensure that they would be very hungry at the time of the 
evaluation. The larvivorous activity was evaluated by making a comparative count of the number of winged insects that emerged in the 2 aquaria.

With the goal of evaluating whether the consumption of larvae by the fish was a preference or simply motivated by the lack of other food options, 5 other experiments were conducted by offering the fish, exclusively or simultaneously, larvae or granulated fish food (the same food used in pisciculture). We offered 1000 larvae and 20 pellets of fish food to 1 fish per aquarium. This amount of fish food was established on the basis of the recommendation of fish farmers, equivalent to approximately $10 \mathrm{~g} / \mathrm{kg}$ of fish. The proportional consumption of each type of food offered was compared after a $60-\mathrm{h}$ observation period, both in the morning and in the afternoon of the day of feeding.

\section{Data Analysis}

All data gathered in the experiments were recorded in MS Excel tables and later exported to Epi-Info version $6.04 \mathrm{~b}$. The results were described in absolute and relative frequencies, with respective confidence intervals of $95 \%$. Comparisons between proportions were performed using the chi-square test, and comparisons between medians were performed using Median test, taking into consideration an alpha error of $5 \%$.

\section{RESULTS}

The water temperature during the research period oscillated between $21^{\circ} \mathrm{C}$ and $26^{\circ} \mathrm{C}$ [mean (SD): $23.6^{\circ} \mathrm{C}\left(1.3^{\circ} \mathrm{C}\right)$ ], and air temperature between $23^{\circ} \mathrm{C}$ and $29.8^{\circ} \mathrm{C}$ [mean (SD): $\left.25.7^{\circ} \mathrm{C}\left(1.9^{\circ} \mathrm{C}\right)\right]$. Relative humidity was between $38 \%$ and $80 \%$ [mean (SD): $66.7 \%(10.9 \%)$ ].

\section{Examination of $O$. kneri Stomach Content}

From the analysis of stomach content, it was found that, in their natural habitat, $O$. kneri consumed a wide variety of food items. The predominance, both in terms of volume and proportion, was of food residues indicative of mollusks $(40.9 \%)$, diverse organic matter $(27.7 \%)$, and annelids and worms $(12.1 \%)$. We also observed that $11.5 \%$ of the stomach content consisted of larvae of the order Diptera and 3.0\%, larvae of other insect orders.

\section{Observation on the Consumption of Culicidae Larvae in Aquaria}

Total observation of the emergence period of the adult insects from insect larvae was approximately $132 \mathrm{~h}$. However, the distribution of the emergence periods during that time was rather asymmetric, with mode, median, and mean of 60,69 , and $82 \mathrm{~h}$, respectively. In addition, the emergence time was not influenced by the presence of $O$. kneri, since the temporal distribution of the number of larvae emerging into adult insects was similar during the entire observation period, irrespective of whether the aquarium contained fish or not (Fig. 1).

In the experiments to evaluate the larvivorous activity of the fish, it was demonstrated that after $60 \mathrm{~h}$ of observation, only $1(0.03 \% ; 95 \% \mathrm{CI}=0-0.24 \%)$ emergence from larva to adult insect was observed in the 3 test aquaria, where we placed a total of 2700 larvae. In this same period of observation, the control aquarium showed an emergence of 921 (34.1\%; 95\% CI $=32.3-35.9 \%)$ larvae into adult insects. The difference between the number of emerging larvae in tanks with and without fish was statistically significant $(\mathrm{p}<$ 0.0001). The experiments were interrupted during this observation period because there were no more larvae available to emerge in the test aquarium. In fact, no adult insect was observed on the protective screen of the test aquarium in the 3 days following the experiment (Table 1).

\section{Comparison of Larvae and Fish Food Pellets Consump- tion}

A similar proportion was recorded for the average consumption of granulated fish food or larvae, even when these food items were offered simultaneously (Table 2).

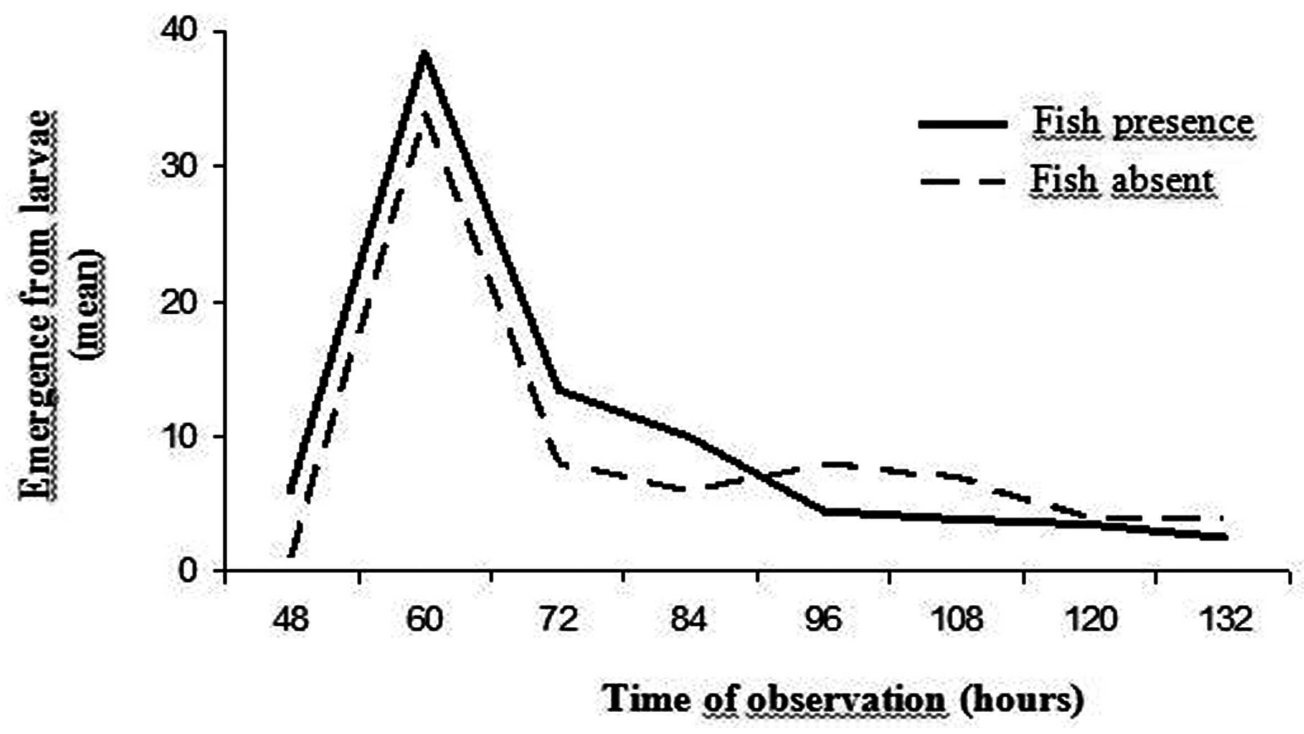

Fig. (1). Temporal trends of emergence of larvae [Culex spp and Aedes (Ochlerotatus) fluviatilis] to adult insects in the presence and absence of fish in an aquarium Oxydoras kneri. 
Table 1. The Experiments' Results of the Observation on the Fish Predation O. kneri with Larval [Culex spp and Aedes (Ochlerotatus) fluviatilis] Offered in Experimental Aquarium

\begin{tabular}{|c|c|c|}
\hline \multirow{2}{*}{ Evaluation parameter } & \multicolumn{2}{|c|}{ Aquarium } \\
\cline { 2 - 3 } & Test & Control \\
\hline \hline $\begin{array}{c}\text { Observation time } \\
\text { (horas) }\end{array}$ & 60 & 2700 \\
\hline $\begin{array}{c}\text { Larvae offered } \\
(\mathrm{n})\end{array}$ & 2700 & $<0,0001^{*}$ \\
\hline $\begin{array}{c}\text { Larvae's Emergence for adults } \\
\mathrm{n}(\%)\end{array}$ & $1(0,24)$ & $921(34,1)$ \\
\hline
\end{tabular}

* Fisher's exact test

Table 2. Evaluation's Results for Feeding Preference of Oxydoras Kneri Fish, Larvae [Culex spp and Aedes (Ochlerotatus) fluviatilis] and / or Fish Food in Experimental Aquarium

\begin{tabular}{|c|c|c|c|c|c|}
\hline \multirow[b]{2}{*}{ Experiment } & \multicolumn{5}{|c|}{ Consumed itens } \\
\hline & Larvae & Fish food & $\mathbf{p}$ & Larvae+fish food & $\mathbf{p}$ \\
\hline $1^{\mathrm{o}}$ & 96 & 80 & \multirow{5}{*}{$0,15^{*}$} & $100 / 20$ & \multirow{5}{*}{$0,08^{*}$} \\
\hline $2^{\circ}$ & 100 & 100 & & $100 / 80$ & \\
\hline $4^{\circ}$ & 90 & 70 & & $98 / 85$ & \\
\hline $5^{\circ}$ & 90 & 30 & & $50 / 15$ & \\
\hline Mean (SD) & $90,2(9,5)$ & $74,0(27,0)$ & & $85,6(21,6) / 56(35,2)$ & \\
\hline
\end{tabular}

Note: For all experiments we used a sample of $O$. Kneri and offered 1000 larvae and 20 grains of fish food. * $p$ values calculated by Student's t test, comparing the mean proportions of the two food items consumed separately or simultaneously.

In addition, we observed intense vertical movement of $O$. kneri in the aquarium and more feeding activity at the water's surface. In less than $48 \mathrm{~h}$, more than $80 \%$ of the larvae or the fish food offered was consumed in majority of the experiments. The difference in proportional consumption observed between the 2 food items was not statistically significant (Table 2). However, it was possible to observe that, immediately after these food items were offered, the pellets of fish food ingested simultaneously with the larvae were eliminated via the operculum, while the larvae were completely ingested by the fish.

\section{DISCUSSION}

Different species of fish have been used in the biological control of the larvae of disease-vector mosquitoes, both in natural breeding sites and under artificial breeding conditions [2,4,10-15]. However, little is known about the role of the fish of the genus Oxydoras in this context, although there are some records of the presence of Diptera larvae in studies evaluating the feeding behavior of Oxydoras fish [7].

In general, studies on the biological control of vectors by using larvivorous fish have been conducted using species ranging from 2 to $34 \mathrm{~cm}$ in length $[2,15,16]$. In this study, the possible role of fish of the genus Oxydoras in the biological control of larvae was evaluated for the first time. The initial observations of a considerable proportion of Diptera insect larvae in the stomach content of $O$. kneri from the wild, confirmation of the fish's larvivorous behavior in aquaria, and the fact that the ingested larvae were not eliminated through the operculum, indicate the possibility of using this species in the biological control of insects in pisciculture tanks, without competition for fish food with other species of fish considered more desirable for human consumption. These findings are corroborated by the results of another study conducted in the region that showed that, despite its omnivorous habits, O. kneri does include Diptera larvae among its preferred food items [7].

The finding that the emergence time was not influenced by the presence of $O$. kneri guaranteed the comparability of the results observed in both the test and control aquaria in the experiments to evaluate the larvivorous behavior of the fish. Therefore, the considerable difference observed in the emergence ratio from larvae into adult insects in the aquaria, with or without the presence of $O$. kneri, was decisive in this study for highlighting the larvivorous habit of this species of fish. 
The use of this method to identify and measure the intensity of said larvivorous behavior was justified because of the impossibility of accounting for the food items offered, considering the size and volume of the aquaria used in the experiments. Even as an indirect measure of the main effect of this study, this option allowed us to reliably evaluate the availability of larvae during their complete biological development, which is directly related to their consumption in the aquaria, either by predation or mortality due to a hostile environment. Once the result observed in the control aquarium excluded the possibility that the larvae died naturally, we could conclude with certainty that the minimum emergence of the larvae into adult insects observed in the test aquarium was due to the larvivorous behatior of $Q$ kneri.

. kneri or a similare promising in terms of using $O$. kneri or a similar species present in the Amazon Basin, $O$. niger, in the control of larvae in pisciculture tanks. Nevertheless, since the larvivorous activity was only observed in the laboratory for this study, some considerations must be made with respect to possible problems resulting from the introduction of these species into an artificial environment for commercial purposes.

In this study, we did not evaluate whether the coexistence of this species of Oxydoras and the species bred in pisciculture tanks could lead to the predation of fingerlings and young fish or to competition for the same food. The observations made by Lauzane and Loubens [17] regarding $O$. niger showed benthonic fauna as the main food source of this species, as well as the fact that during drought periods, there is an increase in the consumption of insect larvae and bivalve and gastropod mollusks; this finding has also been reported by other studies [7]. Since these studies do not show fish fragments or even vegetation preferred by species commonly created for commercial purposes, it is reasonable to assume that $O$. kneri is not a potential predator of the species commonly bred in pisciculture. Likewise, $O$. kneri does not seem to compete for the fish food used in pisciculture, since the consumption of larvae observed in this study was more voracious than that of the fish food offered. In addition, the elimination of the fish food pellets via the operculum, when offered simultaneously with the larvae, also corroborates this hypothesis. However, the relationship between the food habits of $O$. kneri and other typical pisciculture fish species could be an area of interest for future research.

There are some limitations to this study. Since the stomach content of $O$. kneri changes greatly over the course of the year, the results of the study do not necessarily reflect the real feeding behavior of the fish. Another issue relates to the benthonic habitat of the fish and the surface habitat of the culicine larvae. However, during the aquaria experiments, we verified that larger quantities of larvae were ingested at the surface of the water rather than at other depths. Although this species of Oxydoras lives naturally amidst debris at the bottom of rivers and lakes [17] it is possible for them to be captured at several different depths when they are in search of food (information provided by local fishermen). This observation is relevant because of its expected larvivorous capacity in the biological control of vectors, and it was confirmed by the great vertical movement observed in the fish studied in the aquaria when larvae were offered. Therefore, the efficacy of $O$. kneri as a biological control can only be demonstrated with a mesocosm study involving multiple tanks that resemble the environment commonly found in pisciculture.

\section{CONCLUSION}

The findings of this study reveal relevant aspects of the feeding habits of $O$. kneri, suggesting its potential role in the biological control of tropical disease vectors. Although it is the largest of the fish studied for this purpose [15], it has been demonstrated that $O$. kneri eats culicine larvae that are of medical interest and has shown a preference for this particular food item when offered simultaneously with extruded fish food. This is an important aspect, since this species of fish is ubiquitous in the Amazon region and can be used in the biological control of larvae growing in pisciculture tanks. However, further studies to evaluate its behavior in the field and the operational difficulties of its use as a biological control should be performed. In addition, its use for this purpose should be further discussed with social, economic, and environmental authorities, to establish technical standards for handling and commercialization.

\section{CONFLICT OF INTEREST}

The author(s) confirm that this article content has no conflicts of interest.

\section{ACKNOWLEDGEMENT}

Declared none.

\section{REFERENCES}

[1] Rojas PE, Gamboa BM, Villalobos RS, Cruzado VF. Eficacia del control de larvas de vectores de la malaria con peces larvõvoros nativos en San martõn, Perú. Rev Peruana Med Exp Sal Pub 2004; 21: 44-50.

[2] de Goes Cavalcanti LP, Soares Pontes RJ, Ferreira Regazzi AC, et al. Efficacy of fish as predators of Aedes aegypti larvae, under laboratory conditions. Rev Saud Pub 2007; 41: 638-44.

[3] Tadei WP, Pinto RC, Oliveira EM, Terrazas WC, Santos MMJ, Rodrigues IB. Controle de malária em Manaus: Tanque de piscicultura e sua importância na proliferação de Anopheles darlingi. 57 Reunião Anual da SBPC. Fortaleza 2005; p. 500.

[4] Rodrigues IB, Tadei WP, Santos RLC, Santos S, Baggio JB. Controle da malária: eficácia de formulados de Bacillus sphaericus 2362 contra larvas de espécies de Anopheles em criadouros artificiais tanques de piscicultura e criadouros de olaria. Rev Patol Trop 2008; 37: 161-76.

[5] Howard AFV, Omlin FX. Abandoning small-scale fish farming in western Kenya leads to higher malaria vector abundance. Acta Trop 2008; 105: 67-73.

[6] Costa, EAM, Silva, CF, Souza, AFBC, Agostinho, CS, Neamb, UFT. Espectro alimentar de Oxydoras niger (Ostechthyes, Doradidae) no Rio Tocantins. In: XXV Congresso Brasileiro de Zoologia; 2004; Brasília. Anais do XXV Congresso Brasileiro de Zoologia.. Brasilia. v. único 2004.

[7] Marques SP, Costa FES, Zunitni D, Vicentin W, Barboza EG. Levantamento da dieta alimentar e aspecto reprodutivo de $O$. kneri (Armal) da região de cabeceira do rio Miranda, município de Jardim, MS, Projeto Piracema. IV Simpósio sobre Recursos Naturais e Sócio-econômico do Pantanal 2004; p. 500.

[8] Consoli RAGB, Lourenço-de-Oliveira R. Principais mosquitos de importância sanitária no Brasil. $2^{\text {nd }}$ ed. Rio de Janeiro: FRIOCRUZ 1994; p.228. 
[9] Hechtel LJ, Juliano SA. Effects of a predator on prey metamorphosis: Plastic responses by prey or selective mortality? Ecology 1997; 78: 838-51.

[10] Koldenkova L, Famthingoc D, García Avila I, García García I. Feeding of the young of the larvivorous fish Poecilia reticulata (Cyprinodontiformes: Poeciliidae) in a natural breeding site of Culex quinquefasciatus (Say, 1823). 1989; 41: 40-8.

[11] Fletcher M, Teklehaimanot A, Yemane G, Kassahun A, Kidane G, Beyene Y. Prospects for the use of larvivorous fish for malaria control in Ethiopia - search for indigenous species and evaluation of their feeding capacity for mosquito larvae. J Trop Med Hyg 1993; 96: 12-21.

[12] Lardeux F, Sechan Y, Loncke S, Deparis X, Cheffort J, Faaruia M. Integrated control of peridomestic larval habitats of Aedes and Culex mosquitoes (Diptera: Culicidae) in atoll villages of French Polynesia. J Med Entomol 2002; 39: 493-8.
[13] Martinez-Ibarra JA, Guillen YG, Arredondo-Jimenez JI, Rodriguez-Lopez MH. Indigenous fish species for the control of Aedes aegypti in water storage tanks in Southern Mexico. Biocontrol 2002; 47: 481-6.

[14] Nelson SM, Keenan LC. Use of an indigenous fish species, Fundulus zebrinus, in a mosquito abatement program - a field comparison with the mosquitofish, Gambusia affinis. J Am Mosq Control Assoc 1992; 8: 301-4.

[15] Chandra G, Bhattacharjee I, Chatterjee SN, Ghosh A. Mosquito control by larvivorous fish. Indian J Med Res 2008; 127: 13-27.

[16] Manna B, Aditya G, Banerjee S. Vulnerability of the mosquito larvae to the guppies (Poecilia reticulata) in the presence of alternative preys. J Vector Borne Dis 2008; 45: 200-6.

[17] Lauzanne L, Loubens G. Peces del Río Mamoré. Collection Travaux et Documents. Orstom-Cordebeni-UTB, n. 192, p.116, 1985.

Received: March 06, 2013

Revised: April 21, 2013

Accepted: May 03, 2013

(C) Ribeiro et al.; Licensee Bentham Open.

This is an open access article licensed under the terms of the Creative Commons Attribution Non-Commercial License (http://creativecommons.org/licenses/by-nc/3.0/) which permits unrestricted, non-commercial use, distribution and reproduction in any medium, provided the work is properly cited. 